\title{
GROUNDING SYSTEM ADEQUACY OF HV/MV SUBSTATIONS IN AREAS WITH REDUCED ACCESSIBILITY
}

\author{
G. Parise (L.F. IEEE), L. Parise (M. IEEE), \\ L. Martirano (S.M. IEEE) \\ DIAEE Electrical Engineering, \\ Sapienza University of Rome, Italy \\ parise@ieee.org; 1.parise@ieee.org; martirano@ieee.org
}

\author{
Alex Farber, Boris Katz \\ Israel Electric Company, \\ Central Electric Laboratory \\ Haifa, Israel \\ alfar@bezeqint.net
}

\begin{abstract}
The adequacy of grounding systems has to be verified periodically in the operational time. With urban development and buildings growth adjacent to power systems as HV/MV substations, it is very rare to have area around with sufficient accessibility for installing the potential and current electrodes. This paper discusses a safety criterion to verify the effectiveness of a grounding system. This criterion suggests conservative tests for both ground potential rise and touch voltages and step voltages that allow to verify the grounding systems effectiveness in areas with reduced accessibility and to monitor its evolution in the time.
\end{abstract}

Keywords: Current auxiliary electrodes, grounding systems, grounding tests, measurements of touch and step voltages, substation grounding systems

\section{I - INTRODUCTION}

Protection against electric shock requires grounding systems must guarantee to keep touch voltage $\left(\mathrm{U}_{\mathrm{t}}\right)$ and step voltage $\left(\mathrm{U}_{\mathrm{s}}\right)$ to a safe permissible value.

The touch voltage $U_{t}$ is the potential difference between the ground potential rise (GPR) $U_{G}$ of a grounding grid or system and the surface potential where a person could be standing while at the same time having a hand in contact with a grounded structure or object. Figure 1 shows the ground potential profile during a ground fault: $U_{G}$, is the maximum electrical potential that the grounding system might attain relative to a distant grounding point assumed to be at the potential of remote earth [1]. The GPR is equal to the product between the current to ground $\mathrm{I}_{\mathrm{G}}$, part of the ground fault current $\mathrm{I}_{\mathrm{F}}$, and the ground resistance $\mathrm{R}_{\mathrm{G}}$ (or impedance $Z_{G}$ ) of the ground grid $G$.

The step voltage $U_{s}$ is the difference in surface potential that could be experienced by a person bridging a distance of $1 \mathrm{~m}$ with the feet without contacting any grounded object [1].

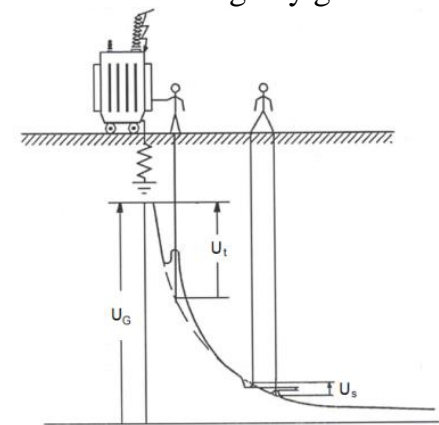

Figure 1. The ground potential rise (GPR) $U_{G}$, the touch voltage $U_{t}$ and the step voltage $U_{s}$.

Testing of the effectiveness of a grounding system is mandatory to verify the adequacy to satisfy the protection requirements in the operational time.

The effectiveness is verified either one of the conditions is fulfilled:
- the ground potential rise (GPR) $U_{G}$ is below the permissible prospective limit value for the fault tripping duration $[2,3]$.

- touch voltages inside and in the vicinity of the grounding system are below the permissible limits.

To verify the first condition that GPR meets the safety requirements relieves from making measurements of touch voltages in the various locations where needed.

The grounding system of HV/MV substations consists of the ground grid and all other extended grounding conductors connected to it. Large grids $\left(>40,000 \mathrm{~m}^{2}\right)$, buried in lowresistivity earth $(<75 \Omega-\mathrm{m})$ without connection to extended grounds, present a reactive component not negligible. The impedance $\mathrm{Z}_{\mathrm{G}}$ may be higher than the estimated resistance by formula available in literature (IEEE Std 80) and the impedance phase angle will be in the $35^{\circ}$ to $40^{\circ}$ range [4]. When extended ground conductors are connected to the grid, grounding-system impedance will be less than estimated grid resistance.

The grounding wires of the power lines connect the substation HV/MV grounding system with the grounding system of all the towers. The main contributor of the reactive component (reactance) of $\mathrm{Z}_{\mathrm{G}}$ is outgoing power lines grounding wire inductivity. In fact, overhead grounding wires that connect to towers and grids will have impedance angles in the $50^{\circ}$ to $85^{\circ}$ range [4].

The substation ground grid only drains the $\mathrm{I}_{\mathrm{G}}$ part of the fault current $\mathrm{I}_{\mathrm{F}}$, while the grounding wires of the power lines drain the other part of the fault current. The impedance angle appears so an index of the draining contribution $\mathrm{I}_{\mathrm{G}} / \mathrm{I}_{\mathrm{F}}$.

Instead, the active (resistive) part of $\mathrm{Z}_{\mathrm{G}}$ comprises of the resistance between a grounding system and the ground. This component depends of conductor's quantity, system configuration and soil resistivity.

\section{GPR measurement: the fall-of-potential method}

There are several methods for measuring GPR of grounding systems. Among them, the fall-of-potential method is most widely applied for almost all types grounding systems, as proven in many field tests [1-5]. All measurements are performed with the grounding system in its normal operative configuration, which kept all external connections in place.

In order to measure the GPR of a substation, it is necessary to apply a voltage between the substation grounding system and the remote auxiliary current electrode $C$ that causes the circulation of a current through it (Figure 2). A potential probe $\mathrm{P}$ is placed at various positions between the current electrode and the grounding system.

The potential curve is plotted against the distance from the substation (Figure 2). The required value of the GPR that allows to define the $R_{G}$ (or $Z_{G}$ ) of the ground grid $G$, is 
located on the resultant curve in the vicinity of a point matching potential wire length $(0.5-0.7$ of the current wire length, theoretically 0.62 ).

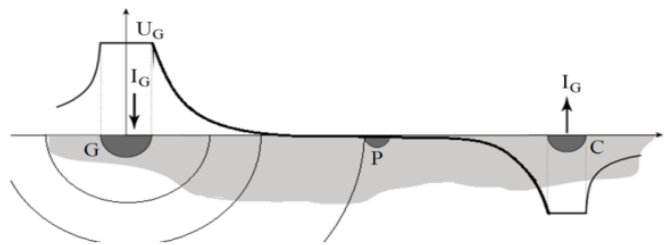

Figure 2. Potential profile between the ground electrode $\mathrm{G}$ and the auxiliary current electrode $\mathrm{C}$.

The greatest difficulty regards the location of the auxiliary electrode C; particularly it has to be placed to a distance d, outside the area of influence $d_{i}$ of grounding system $G$. Usually, it is recognized that the distance $d$ is sufficient, measured from the border contour of the grounding system, when equal at least to 4 times its maximum length [3]. The maximum length of a grounding network is the diameter D of the equivalent circumscribed circle.

The position of the potential probe $\mathrm{P}$ with regard to the auxiliary current electrode may differ.

Electrical testing devices of grounding systems allow directly defining the $Z_{G}$ and its phase angle with excellent interference suppression that facilitates measurement of small signals.

The GPR that defines the $Z_{G}$ is measured situating the wires of the current and voltage electrodes mainly in two conditions:

- parallel with $0^{\circ}$ between them affected by coupling effect $\mathrm{CE}\left(\operatorname{method} 0^{\circ}\right)$

- perpendicular with $90^{\circ}$ between them without $\mathrm{CE}$ $\left(\right.$ method $\pm 90^{\circ}$ )

\section{Fall-of-potential method $0^{\circ}$}

The measured maximum voltage that defines the measured impedance $\mathrm{Z}_{\mathrm{M}}$ on reference to the measurement situating the electrode wires parallel with a $1 \mathrm{~m}$ gap, generally consists of two components:

1) the actual maximum voltage difference between the grounding system under test and the potential probe that defines the $\mathrm{Z}_{\mathrm{G}}$,

2) the "coupling effect", the inducted potential that defines the related impedance $Z_{C E}$ is due to alternating current flowing in the current test loop [4].

The complex nature of the parameters requires considering the amplitude and the phase angle for substation grounding impedance $Z_{\mathrm{G}}, \varphi_{\mathrm{G}}$ and coupling effect $\mathrm{Z}_{\mathrm{CE}}$, $\varphi_{\mathrm{CE}}$.

Measured impedance $Z_{M}, \varphi_{M}$ is conservative, in fact it is the sum of two vectors, actual grounding impedance and the coupling effect that has to be known and at this aim a parametric method has been performed [6,7].

Thus, actual grounding impedance $Z_{\mathrm{G}}, \varphi_{\mathrm{G}}$ can be calculated by vector subtraction of the coupling effect $Z_{\mathrm{CE}}, \varphi_{\mathrm{CE}}$ from the measurement result $\mathrm{Z}_{\mathrm{M}}, \varphi_{\mathrm{M}}$

$$
\begin{aligned}
& Z_{G}=\sqrt{Z_{M}{ }^{2}+Z_{C E}{ }^{2}-2 Z_{M} Z_{C E} \cos \left(\varphi_{C E}-\varphi_{M}\right)} \\
& \varphi_{G}=\operatorname{arcos}\left(\left[Z_{M} \cos \left(\varphi_{M}\right)-Z_{C E} \cos \left(\varphi_{C E}\right)\right] / Z_{G}\right)
\end{aligned}
$$

In the Figure 3, $\mathrm{C}$ is the auxiliary current electrode, $\mathrm{I}_{\mathrm{G}}$ is the measured current, $\mathrm{P}$ is the potential electrode and $\mathrm{V}$ is the measured voltage in the point $\mathrm{P}$.

\section{Fall-of-potential method $90^{\circ}$. Comparison between the two} method

The method to be used by testers is situating the electrode wires with $90^{\circ}$ between them (method $\pm 90^{\circ}$ ). The clear advantage of this method is the lack of the coupling effect with $\mathrm{Z}_{\mathrm{CE}}=0$.

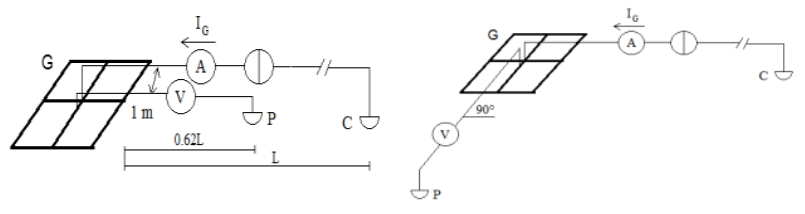

Figure 3. Methods $0^{\circ}$ and $90^{\circ}$ of impedance measurement in a grounding system.

Positioning the potential probe in line with the current electrode $\left(\operatorname{method} 0^{\circ}\right.$ ) enables detection of eventual objects in the ground - water pipes, large metal bodies, etc. An insert will deform the shape of the curve. When the deformed curve is obtained during measurements, the testing technician selects another direction from the substation to perform the measurement, thereby reducing the inaccuracy in the measurement results. However, due to the abovedescribed coupling effect, the results will be higher than the actual grounding resistance value.

Let us consider that positioning the current and potential electrodes with $90^{\circ}$ between them (method $\pm 90^{\circ}$ ) or at opposite sides $\left(\right.$ method $\left.180^{\circ}\right)$ present the shortcoming that lies in the impossibility of controlling underground conducting objects. For example, a steel pipe lying underground parallel to the potential wire reduces the measured voltage without distorting the shape of the potential/impedance curve. Moreover the method $180^{\circ}$ does not eliminate the coupling effect which is now no conservative.

\section{II - MEASUREMENT ACCURACY AND SAFETY CRITERION}

To verify the effectiveness of grounding systems the measurements of touch and step voltages $\left(U_{t}, U_{s}\right)$ and of ground resistance $R_{G}$ or impedance $Z_{G}$ present some operational difficulties.

Accuracy of tests requires reaching remote earth and for large grounds, the spacing required may not be practical or even possible. Unfortunately, accurate measure is often unfeasible.

To verify the grounding system of a great HV/MV substation as an industrial or commercial complex, the influence distance $d_{i}$ can reach some kilometers. Such distance involves, besides the obvious problems of execution, a rise of interference and an increase of the effect of electromagnetic coupling between the conductors of measuring circuit.

The grounding system under test will result in lower measured impedance if the current or potential electrodes are installed near grounded metal structures or other grounding conductors are interfering with the same grounding systems. With urban development and buildings growth adjacent to power systems, grounding systems, also if not metallically 
connected, are significantly interdependent as they are located in each other's area of influence. This situation causes a series of problems in terms of electrical compatibility and personnel safety. It becomes increasingly difficult to choose suitable locations for auxiliary electrodes to make tests of resistance and $U_{t}$ and $U_{s}$ of a grounding system.

In the presence of background and interference voltages, the measurement accuracy will depend mainly on the length and routing of the test conductors, the magnitude of the test current (and the resulting voltage drop across grounding impedance), and the selectivity and sensitivity of the method used to measure the potential magnitude and its phase angle relative to the current.

Since the rigorous measure can result too much laborious or too much expensive, an appropriate conservative criterion can be decisive for testing the grounding system effectiveness.

This paper discusses the safety criterion of assuring conservative measurements to verify the effectiveness of a grounding system. If the feasible measurements of the GPR or of the touch voltages are with a limited accuracy, but their values are conservative due to their positive error increasing the prospected true value, they are acceptable to verify the safe effectiveness of grounding systems.

In fact, if the measured values are lower than the values permissible for the fault tripping duration, the safe effectiveness of the grounding system is verified.

By means of this criterion, conservative tests are suggested for both $\mathrm{U}_{\mathrm{G}}$ (that is $\mathrm{Z}_{\mathrm{G}}$ ) and touch voltage $\left(\mathrm{U}_{\mathrm{t}}\right)$ and step voltage $\left(U_{s}\right)$, since that these methods guarantee errors positive and so their consideration results conservative.

The suggested test for measuring grounding system resistance/impedance is the fall-of-potential method $0^{\circ}$, prospecting of positioning the potential electrode in line with the remote current electrode that allows conservative measurements $\left(\mathrm{Z}_{\mathrm{M}}\right)$.

The suggested test of touch and step voltage measures can be done with a single auxiliary electrode or multiple auxiliary electrodes placed at a reduced distance.

Whenever it is possible, it is always convenient to measure the resistance of the grounding system and to evaluate the GPR. To verify that GPR meets the safety requirements is a condition sufficient to guarantee the effectiveness of the grounding system and therefore, as already observed, to relieve from making measurements of touch voltages in the various locations where needed.

\section{III - CONSERVATIVE GROUND IMPEDANCE MEASUREMENTS}

\section{Conservative fall-of-potential method $0^{\circ}$}

Modern substations are usually located in the built up zones and it can be difficult or impossible to find directions free of transmission lines, buildings or underground communications to spread the measuring wires.

Certainly, it could be easier to find a reduced sector or at least one direction free of interferences. In these situations, the unique possible method of measurement is the parallel method $0^{\circ}$ that always will result conservative.

In fact, due to the above-described coupling effect, the $Z_{M}$ results will be higher than the actual grounding impedance value $\mathrm{Z}_{\mathrm{G}}$. When it is likely to repeat the measurements adopting an angle higher than $0^{\circ}$, it will be possible to test lower values of $\mathrm{Z}_{\mathrm{M}}$ more suitable to assume.

\section{Mutual coupling calculation for standard conditions}

For calculating the coupling effect, a parametric method has been performed considering standard conditions (FarberKatz method) [6,7]. The amplitude and phase angle of the $\mathrm{Z}_{\mathrm{CE}}$ have been defined by numeric methods solving the expression available in literature for calculating the mutual impedance between two insulated wires lying on the earth's surface, of finite length.

The standard conditions assumed for the definition of $\mathrm{Z}_{\mathrm{CE}}$ consider as current wire lengths up to $3000 \mathrm{~m}$ and potential wires up to $2000 \mathrm{~m}$, as soil resistivity values in the range $1 \div 10,000 \Omega \mathrm{m}$, as distance between the current and potential parallel wires is assumed 1 meter from each other.

Based on these results, a family of coupling effect curves was calculated to evaluate the amplitude and the phase angle $\varphi_{\mathrm{CE}}$ of $Z_{\mathrm{CE}}$ for different soil resistivity, for any current wire lengths up to $3000 \mathrm{~m}$ and potential wires up to $2000 \mathrm{~m}$ (Figures 4 and 5).

To validate the parametric approach, grounding tests were conducted at three substations of $170 / 24 \mathrm{kV}$ located in rural areas. The sites were checked to ensure there was no underground communication that could influence the measurements. The tests were performed using the methods $0^{\circ}$, with a $1 \mathrm{~m}$ gap between the two test wires, and $90^{\circ}$.

In every case the current and the voltage electrodes were established, it has to be made sure the electrode wires were long enough to reach the remote earth. The measurement system enabled directly measuring the complex value of ground resistance impedance with the phase angles.

The value of the coupling effect can be easily found with the help of the curves in Figures 4 and 5 by using the value of the soil resistivity of the area, where the grounding system is installed and the lengths of the potential wire are known. Soil resistivity measurements are performed by classic methods as the Wenner method [1].

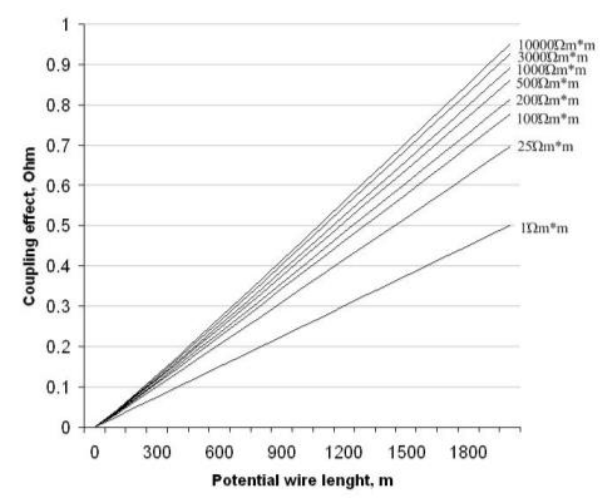

Figure 4. Curves of coupling effect $\mathrm{Z}_{\mathrm{CE}}$ (as impedance amplitude) versus potential wire length up to 2,000 $\mathrm{m}$ and different soil resistivity

The accuracy of the results that can be obtained is influenced by the readability of the curves.

The substation ground impedance $\mathrm{Z}_{\mathrm{G}}\left(90^{\circ}\right)$ was measured directly by the method $90^{\circ}$; the impedance $Z_{G}\left(0^{\circ}\right)$ was determined by subtracting the coupling effect $Z_{C E}$ value from the measured ground impedance $\mathrm{Z}_{\mathrm{M}}$ measured by the method $0^{\circ}$, according to formula (1). 


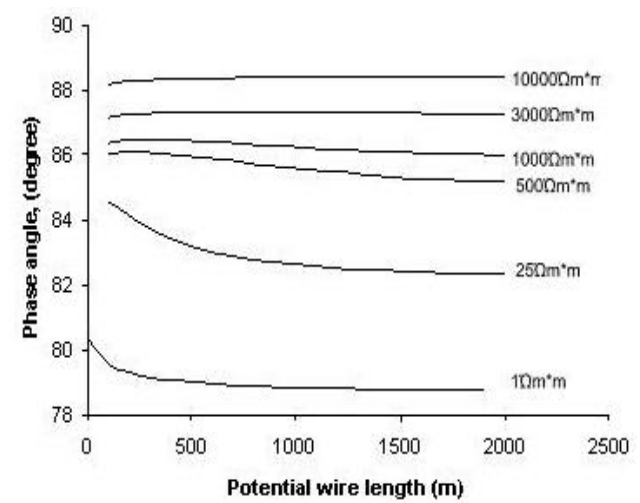

Figure 5. Phase angle $\varphi_{C E}$ in dependence of the potential wire lengths and the soil resistivity for impedance of the coupling effect

Summary of the convergence of the measurement results for the 3 substations are presented in Table I that shows an error $\pm 7 \%$.

Table I. Summary of substation grounding impedance measurement results

\begin{tabular}{||c|c|c|c|c|c|c|c||}
\hline \hline № & $\begin{array}{c}\text { Potential } \\
\text { wire } \\
\mathbf{m}\end{array}$ & $\begin{array}{c}\boldsymbol{\rho} \\
\mathbf{\Omega}^{*} \mathbf{m}\end{array}$ & $\begin{array}{c}\text { Measured } \\
\text { value } \\
\mathbf{\Omega}\end{array}$ & $\begin{array}{c}\text { Coupling } \\
\text { Effect } \\
\mathbf{\Omega}\end{array}$ & $\begin{array}{c}\text { Final } \\
\text { result } \mathbf{0}^{\circ} \\
\mathbf{\Omega}\end{array}$ & $\begin{array}{c}\text { Final } \\
\text { result 90 } \\
\mathbf{\Omega}\end{array}$ & $\begin{array}{c}\text { Results } \\
\text { difference } \\
\%\end{array}$ \\
\hline 1 & 300 & 500 & $0.224 \angle 45^{\circ}$ & 0.095 & $0.164 \angle 23^{\circ}$ & $0.163 \angle 1^{\circ}$ & $+0.6 \%$ \\
\hline 2 & 275 & 50 & $0.170 \angle 29^{\circ}$ & 0.080 & $0.140 \angle 0^{\circ}$ & $0.150 \angle 13^{\circ}$ & $-6.6 \%$ \\
\hline 3 & 200 & 18 & $0.190 \angle 30^{\circ}$ & 0.045 & $0.170 \angle 17^{\circ}$ & $0.160 \angle 17^{\circ}$ & $+6.3 \%$ \\
\hline
\end{tabular}

In any cases, the measured values of impedances $\mathrm{Z}_{\mathrm{M}}$ are higher than the "true" values: if the correspondent GPR values are lower than the permissible ones, they verify the safe effectiveness of the grounding system.

\section{CONSERVATIVE TOUCH POTENTIAL MEASUREMENTS}

In the cases where the area of measurements has a reduced accessibility that is also without one direction free of interferences, the paper suggests a conservative testing method. This method, in any case an alternative way to verify the adequacy of grounding systems, is based on using one or more current electrodes at short distance to verify the effectiveness of grounding system (Parise method) [8-14]. The touch and step voltage measures can be done with auxiliary electrodes at a reduced distance, since that the error is positive and so the results are conservative.

Figure 6 highlights that a C current electrode at short distance influences the behavior of the fault current flow, producing two different distortion effects in ground potential measures:

- a "cut" effect on the actual measured value U' ${ }_{G}$ referred to the true value $\mathrm{U}_{\mathrm{G}}$ so $\mathrm{U}_{\mathrm{G}}$ ' $<\mathrm{U}_{\mathrm{G}}$;

- a "gradient" effect on $U^{\prime}{ }_{t}$ with higher values (conservative) or with lower values (not conservative) than the true ones $U_{t}$.

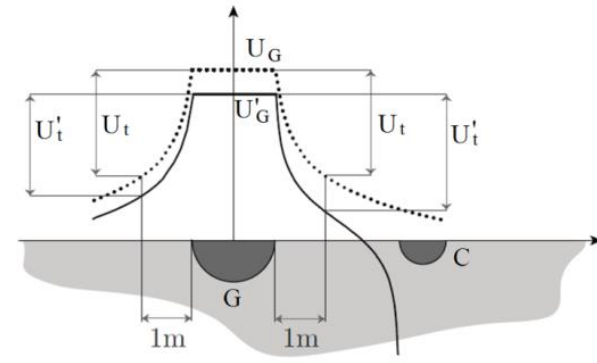

Figure 6. Potential behaviors of a hemispherical electrode with a single $\mathrm{C}$ current electrode at remote point (dashed line) and at short distance (continuous line).

The cut effect is due to the reduction of the ground volume interested by the current flow between the grounding system and the current electrode at shorter distance.

The gradient effect of a single electrode produces an increased flow of the current rate in the soil sector of the grounding system at the side correspondent to the same current electrode (conservative measures) and a more reduced flow in the opposite side (not conservative measures).

The Figure 7 shows a touch voltage $U_{t}$ test done on a line tower footing installed in a corner of HV/MV substation with the footprint-electrode method. The error is incremented of about $+10 \%$ moving the current electrode from $500 \mathrm{~m}$ to $200 \mathrm{~m}$.

The adoption of $n>2$ auxiliary electrodes, symmetrically installed around the grounding system, offers conservative measurements expanded in all the around area. The increasing of the number of auxiliary electrodes growths the accuracy in an alternative way to increase their installation distance (intervention that can be severely limited or impossible).

Moreover, multiple auxiliary electrodes help to ensure greater safety conditions in the execution of the test, since it shares on the same multiple electrodes the test current, reducing the potential that would set globally on the single remote electrode system.

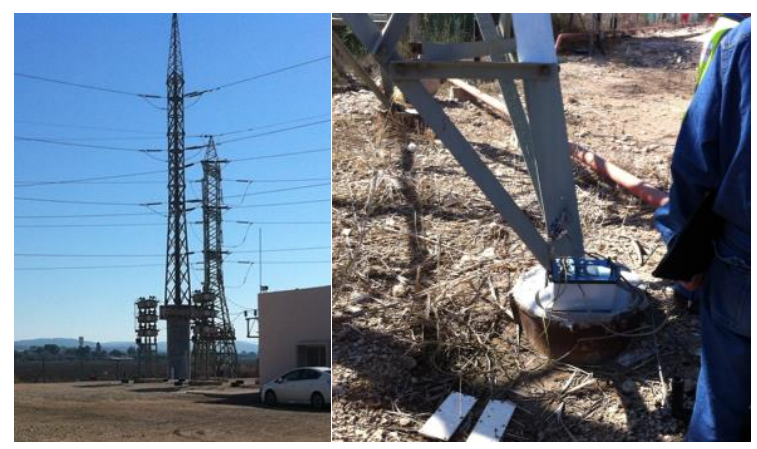

Figure 7. Conservative touch voltage $U_{t}$ tests done on a line tower footing installed in a corner of HV/MV substation in

Kyriat, Israel (Technical team of IEC R\&D Lab. Haifa)

To verify the validity of the proposed method in comparison with the "classical" method with a remote auxiliary electrode outside the zone of influence, tests of touch voltage were taken on the grounding systems of two substations 150/20kV, Industrial Zone 2 and Mineo near Catania (Sicily, 
Italy). In particular, they were used a remote current electrode installed respectively at $30 \mathrm{~km}$ and $3 \mathrm{~km}$ and alternatively four current electrodes installed symmetrically around the grounding systems at $20 \mathrm{~m}$ only (Figures 8 ).

The results confirm the acceptability of the measures based on the safety criterion of satisfying, the permissible requirements also by inaccurate measurements but certainly conservative.

Let us note that the error is always conservative for all the measurement points. The error is always conservative at the reduced distance. The map of the substation highlights four representative measurements The maximum value of the error is equal to $30 \%$ in the case of point 18 of Industrial Zones 2 external to the system but still acceptable because in favor of safety.

The installation of auxiliary electrodes at short distance and their connections can permanently enable the control of the effectiveness level of grounding systems by monitoring the touch voltage of one or more equipment assumed as critical reference. To verify and calibrate the system can perform initial and periodic measurement with the classic method with the auxiliary electrode at a great distance, when possible.

On the basis of the results of a lot of simulations by computerized programs they can be defined as general rules:

- the use of one auxiliary electrode at short distance permits to evaluate the touch and step voltage in the zone between the grounding system under investigation and the auxiliary current electrode with conservative results;

- the use of more symmetrical current electrodes at short distance reduces the errors in all the peripheral zone, outside-inside, around the grounding system, due to the sharing of the test current among the more electrodes

- a good practice is to place current electrodes in proximity of grounding system parts preferably with low current carrying density.

The use of a simulation program for asymmetrical grounding system helps to identify the electrodes location to obtain the best results.
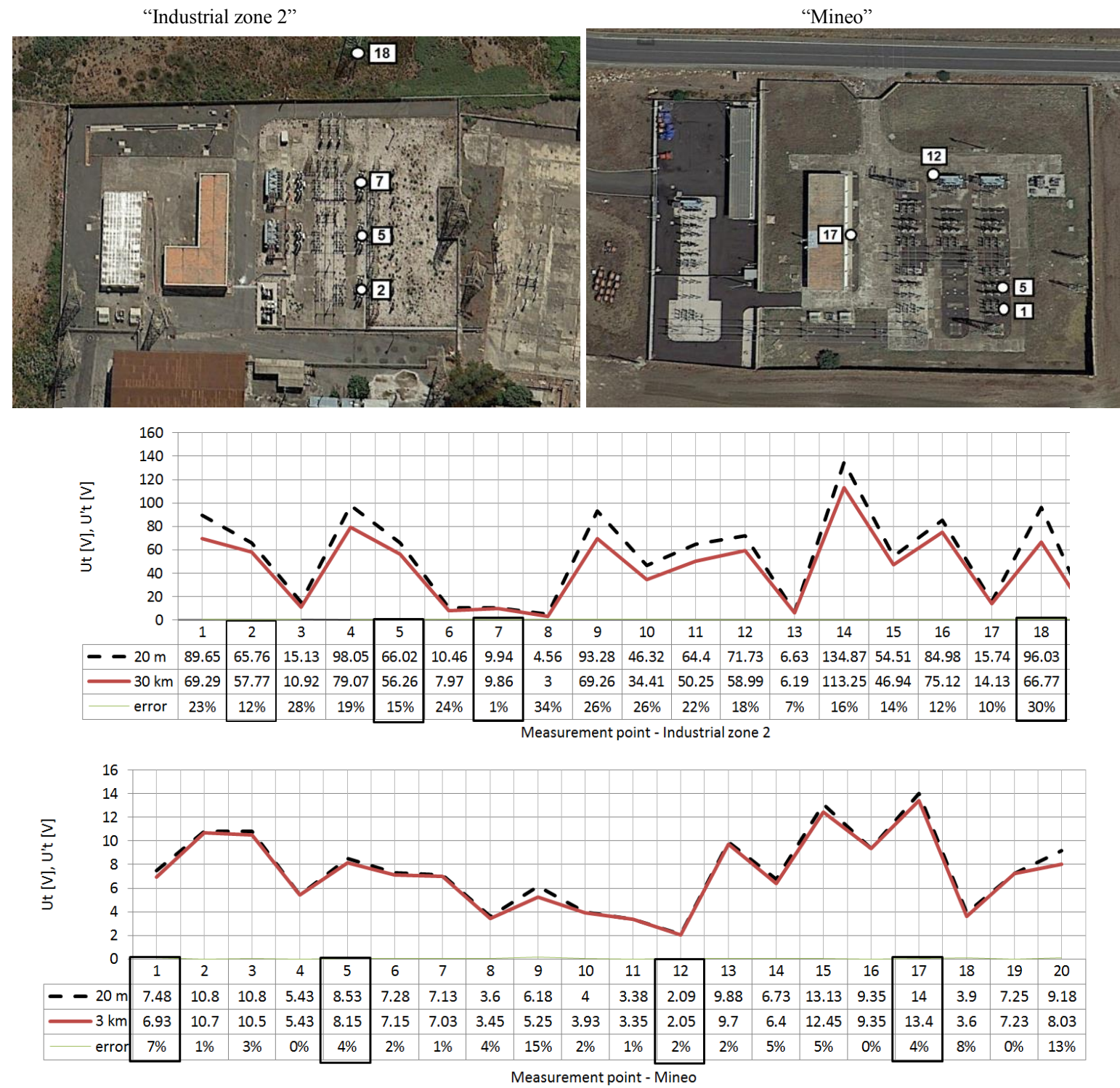

Figure 8 Touch voltage measurements done in the 150/20kV substations "Industrial Zone 2" and "Mineo" (Catania, Sicily, Italy) with the auxiliary current electrode located at $20 \mathrm{~m}$ from the grounding system contour (dashed line in the graph) and at $30 \mathrm{~km}$ and $3 \mathrm{~km}$ respectively (continuous line in the graph). (Performer: Technician Emanuele Falanchi, Enel, Italy). 


\section{V- CONCLUSIONS}

Effectiveness of grounding systems has to be verified periodically in the operational time.

In the urban or industrial areas, buildings growth adjacent to power system as HV/MV substations, it is very rare to have around areas with sufficient accessibility to choose suitable locations for auxiliary electrodes and so rigorous ground resistance measures can result impossible. This paper has suggested methodologies for testing both ground potential rise and touch voltage and step voltage that allow to verify the grounding systems effectiveness in areas with reduced accessibility and to monitor its evolution in the time.

\section{REFERENCES}

[1]. IEEE Std 81 2012- Guide for measuring earth resistivity, ground impedance and earth surface potential of a grounding system.

[2]. IEC 61936-1 Power installations exceeding $1 \mathrm{kV}$ a.c. Part 1: Common rules 2010-11

[3].EN 50522 : 2010-11, "Earthing of Power Installations Exceeding $1 \mathrm{kV}$ a.c.

[4]. IEEE Guide for Safety in AC Substation Grounding, IEEE Standard 80, 2000.

[5]. G. Parise : A new summary on the IEC protection against electric shock, Industry Applications IEEE Transactions on, 2013 Volume: 49, Issue: 2

[6].Farber and B. Katz, "Israel Electric validates earthing measurements", Transmission and Distribution World, vol. 61, pp. 52-56, July 2009.

[7]. Farber and B. Katz, "Coupling effect in substation ground measurements" Serbian Journal of Electrical Engineering vol 9 n.3 October 2012 315-324.

[8]. U.Grasselli, G.Parise: "Touch and Step Voltages Measurements By Auxiliary Electrode at Reduced Distance", L'Energia Elettrica, vol 70, no 10, October 1993, pp 409-415.

[9]. G. Parise, U. Grasselli, P. Peschiulli "Touch And Step Voltages Conservative Measurements Via Auxiliary Short-Distance Electrodes",UPEC '96, September 18-20, 1996 ,vol.3, pp.736739, Iraklio, Crete, Greece

[10]. G.Parise, U. Grasselli: "Simplified conservative measurements of touch and step voltages" 1999 IEEE-IAS ICPS Technical Conference Sparks NV USA May 2-6

[11]. G. Parise, U. Grasselli, R. Iaconelli " Measurements Of Touch And Step Voltages Adopting Multi Current Auxiliary Electrodes" 2000 IEEE-IAS Annual Meeting Roma October 8-12 2000

[12]. G. Parise, M. Lucheroni, "Measurements of Touch and Step Voltages Adopting Current Auxiliary Electrodes at Reduced Distance" 2005 IEEE/I\&CPS Technical Conf., Saratoga Springs, NY, USA, May 8-12, 2005; Transactions IEEE/IAS volume 44 n.6 November December 2008

[13]. P. Buccheri, S. Mangione, G. Parise: "Influence between earthing systems without metallic connection". CIGRE Symposium on High Currents 3-5 giugno 1985 - Bruxelles

[14]. Parise G.; Martirano L.; Parise L.; Celozzi S.; Araneo, R.; Safety criteria for testing ground systems within their influence zone, $14^{\text {th }}$ IEEE EEEIC, 10-12 May, 2014, Krakow, Poland.

\section{BIOGRAPHIES}

Giuseppe Parise (M'82-SM'03-F'10-L.F'15)) is currently a Full Professor of Electrical Power Systems at Sapienza University of Rome and coordinator of the Electrical Engineering Section at the DIAEE Dept. He has been Designer of power electrical systems in buildings complexes as in: the Sapienza University City, the Engineering Faculty, the Polyclinic Umberto I, the Italian
Parliament and the Campus Biomedical Research Center. He has authored about 250 papers and is the holder of two patents and three Prize Paper Awards by IEEE/IAS PSD. Prof. Parise has been a Member of Superior Council of Ministry of Public Works since 1983. He is active in the IEEE Industry Applications Society (past Member at Large of Executive Board) and is chair of Italy Section Chapter IA34, a member expert of International Electrotechnical Commission (IEC), of the Italian Electrical Commission (CEI) and of the Electrical Italian Association (AEIT), the vice President of Association Safety Technology Research for Industry (ASTRI), a past President of AEIT Rome's Section. Since 1975 he has been a Registered Professional Engineer in Italy.

Luigi Parise (StM'06-M'10) received the B.S., the M.S. and Ph.D. degrees in Electrical Engineering from the Sapienza University of Rome, Rome Italy, in 2007, 2009 and 2014 respectively. He is currently Research Fellow at University of Calabria (UNICAL) and he is Tutor in electrical power systems in hospitals in the University Biomedical Campus of Rome. Mr. Parise was a recipient of the 2010 Italian Electrotechnical Committee (CEI) Award for the Best Thesis titled: Electrical Service Continuity In Critical Buildings Protection of Hospitals Against Lightning. He is a member of the Electrical Italian Association (AEIT), the R8/Europe Area Chair of IEEE Industry Applications Society SBCs and the Secretary of Italy Section IAS Chapter. Since 2008, he has been a Registered Professional Engineer in Italy.

Luigi Martirano (StM'98-M02-SM11) is currently a researcher in electrical power systems and assistant professor of Building Automation and Energy Management. At Sapienza University He has authored more than 70 papers in international journals and conferences and one international patent. His research activities cover power systems design, planning, safety, lightings, home and building automation, energy management. He is a senior member of the IEEE/IAS, member of the AEIT (Italian Association of Electrical and Electronics Engineers) and of the CEI (Italian Electrical Commission) Technical Committees CT205 (Home and Building Electronic Systems) and CT315 (Energy Effectiveness). He has been Registered Professional Engineer.

Alexander Farber was born in Moldova, in 1963. He received the $\mathrm{BSc}$ and MSc degrees from Leningrad Polytechnic Institute in Russia, and Ph.D. degrees from Tel Aviv University in Israel in 2011. In 1986, he joined Electroapparat, a USSR-based company, where he worked on the development and design of HV test equipment for GIS. He joined Israel Electric in 1990, working in the Central Electrical Laboratory in the field of substation equipment testing as senior section manager.

Boris Katz was born in Russia, in 1962. He received the BSc EE and MSc degree from Ural Polytechnic Institute in Sverdlovsk, Russia. In 1984, he joined TechEnergo, a USSR-based company, where he worked as test engineer on power stations and industrial sites. He joined Israel Electric in 1990, working in the Central Electrical Laboratory in the field of relay protection testing and test equipment calibration as senior section manager. 